\title{
FÍBULA DE CODO TIPO HUELVA EN EL ENTORNO NORTE DE LA VEGA DE GRANADA
}

\section{AN ELBOW FIBULA OF HUELVA TYPE FOUND IN THE VEGA DE GRANADA REGION}

\author{
por \\ JAVIER CARRASCO RUS y \\ JUAN A. PACHÓN ROMERO
}

\begin{abstract}
RESUMEN El hallazgo de una nueva fíbula de codo 'tipo Huelva', en el borde norte de la Vega de Granada, contribuye a ratificar la importancia del Sureste y, concretamente, de la provincia de Granada en el desarrollo de la metalurgia del Bronce Final hispano. La composición de su aleación, pobre en estaño y con presencia de arsénico, la adscribe al grupo granadino como una producción más de los talleres metalúrgicos existentes, al tiempo que la separa del conjunto de la Ría de Huelva y del oeste peninsular. Por otro lado, su exclusiva decoración con botones de oro le confiere un carácter suntuario que debemos poner en relación con los rituales propios del mundo funerario y de prestigio de las clases sociales eminentes en las últimas comunidades prehistóricas. Todo ello en íntima conexión con los problemas del intercambio de bienes, la precolonización, las interrelaciones mediterráneas y la extensión del uso de tejidos de lujo.
\end{abstract}

\begin{abstract}
The discovery of a new elbow fibula 'type Huelva' in the north border of the Basin of Granada, contributes to ratify the importance of the Southeast and, especifically, of the county of Granada in the development of the metallurgy from the Hispanic Late Bronze Age. The composition of their alloy, wich is poor in tin and posses arsenic presence, connects the elbow fibula to the group of Granada. This clasifiers the elbow fibula as a new product in the metallurgy workshop in Granada. At the some time analysis differentiates this fibula fron the group from the Stuary of Huelva, and in addition from the peninsular west. On the other hand, it's unique decoration, with bellboys of gold, gives it a sumptuary character. This details a connection with the ritual characteristics of the funeral world and prestige of the eminent social classes in de last prehistoric communities. It's intimate connection with the problems of the exchange of goods, the precolonization, mediterranean exchanges and the extension of the use of luxuary textiles.
\end{abstract}

Palabras claves Fíbula de codo de 'tipo Huelva', Ría de Huelva, ritual funerario, taller metalúrgico, intercambio de bienes, prestigio y precolonización.

Key words Elbow fibula 'type Huelva', Stuary of Huelva, funeral ritual, metallurgist workshop, exchange of goods, prestige and pre-colonization. 


\section{INTRODUCCIÓN}

Cuando en 1987 publicamos la pequeña investigación arqueológica realizada en el Cerro de la Miel, al abrigo de las más amplias labores desarrolladas en el cercano Cerro de la Mora (Carrasco, Pachón y Pastor 1985; Carrasco, Pachón, Pastor y Gámiz 1987, Pachón, Pastor y Carrasco 1999), se dio a conocer un pequeño lote de artefactos metálicos del que el más llamativo era una espada de lengua de carpa. No obstante, en el mismo contexto se encontraba igualmente una fíbula de codo tipo Huelva, prácticamente completa, así como la aguja de otra del mismo grupo. Este hallazgo no hubiese tenido mayor importancia respecto del gran depósito fibular conocido en Huelva (Albelda 1923; Díaz 1923; Gómez Moreno 1923; Bosch Gimpera 1926; Almagro Basch 1940a y 1940b; Terrero 1944; Almagro Basch 1957, 1957-58, 1958; Guzzo 1969; Ferrer, García, González, Muñoz y Moro 1997; entre otros) salvo por dos aspectos trascendentales: uno, que la recuperación se realizó asociada a un contenido arqueológico fiable; y dos, que el conjunto se relacionaba directamente con una datación absoluta por C14 (González, Sánchez y Domingo 1987), con la que se aportaba una fecha ciertamente arcaica respecto de las que solían adjudicarse a estas fíbulas por entonces.

La polémica suscitada por tan renovador dato temporal ha quedado reflejada en la bibliografía gracias al profesor M. Pellicer (1986, 1989 y 1993) y, sobre todo, a la Dra. Ma L. Ruiz-Gálvez Priego (1990 y 1993), culminando con el estudio monográfico que sobre el hallazgo de la Ría de Huelva debemos también a esta última investigadora (Ruiz-Gálvez Priego 1995). La activa participación en el debate de nuestro querido y admirado colega don $M$. Pellicer es una de las razones que nos mueve a participar en este merecido homenaje a su dilatada carrera profesional, muy ligada en sus inicios a nuestra Universidad de Granada, y dar a conocer el último ejemplar de fíbula descubierto en Granada, exponer su trascendencia e importancia en el conocimiento de las fíbulas antiguas peninsulares, dentro de los márgenes marcados para esta ocasión. Estos aspectos han centrado gran parte de nuestro trabajo en los últimos veinte años y hemos de admitir que, sin el talante polémico y apasionado de don Manuel, nuestros estudios en esta materia, de igual forma que en otras relacionadas con la prehistoria granadina, hubiesen ido muy posiblemente por otros derroteros.

La controversia a la que hacíamos referencia nos llevó a desarrollar un exhaustivo estudio estadístico y espectrográfico sobre las fíbulas de codo tipo Huelva, en base a los hallazgos existentes y a los que se fueron añadiendo los producidos posteriormente, tratando de buscar una relación clara entre dataciones arcaicas, tecnología metalúrgica y aspectos morfológicos. De todo ello ya se ha se ha culminado una tesis de doctorado (Pachón 1997), varios estudios parciales (Carrasco y Pachón 1998a, 1998b; Carrasco, Pachón, Esquivel y Aranda 1999; Carrasco, Pachón, Adroher y López en prensa) y una monografía que esperamos poder ultimar en poco tiempo (Carrasco y Pachón en prensa).

La investigación desarrollada permite comprobar en esas fíbulas una tendencia tecnológica hacia la mayor concentración de estaño, conforme se avanza en el tiempo y los modelos alteran su fisonomía hacia formas más esbeltas y menos masivas. Esto coincidía a grandes rasgos con una concentración de ejemplares antiguos en Andalucía Oriental, centrados básicamente en Granada, al tiempo que los casos tradicionales conocidos en la Baja Andalucía ocupaban -según los resultados de componentes- un espectro temporal más avanzado. De igual modo, la concentración estadística de casos conocidos confería a la Alta Andalucía un peso específico (Fig. 1) de mayor importancia que anunciaba, al menos para el territorio peninsular ibérico, un origen posiblemente suroriental de la fíbula de codo tipo Huelva.

La diversidad de hallazgos granadinos con los que actualmente se cuenta, con representantes no solo en el Cerro de la Miel (Moraleda de Zafayona), sino en Los Infantes (Pinos Puente), Puerto Lope/Illora, Montejícar, Guadix, etc., que suponen un montante de diez ejemplares entre hallazgos superficiales y estratificados, representan hoy por hoy un conjunto de fíbulas de gran homogeneidad en la Península Ibérica como para justificar suficientemente los argumentos en favor de su antigüedad y génesis. Aquí solo podremos 
desarrollar determinados aspectos en ese sentido, atendiendo al nuevo hallazgo granadino donde concurren características únicas que permiten reafírmar aún más las tendencias interpretativas que venimos desarrollando desde años atrás.

\section{ANÁLISIS DE LA FÍBULA}

\section{III.1. Descripción}

(Fig. 2:1; lám. I). Fíbula de codo casi completa, sin el elemento terminal del pie, ya que conserva parte de su arranque. La aguja permanece completa, al igual que el puente, en el que aún subsisten por entero ambos brazos. El resorte es de dos espiras a la izquierda del puente, que se mantienen completas, gracias al hecho de no haber perdido la aguja. El puente, con sección de media caña, perfil elíptico y aplanado por la base, se decora con dos fajas resaltadas por tres incisiones: las fajas no presentan decoración incisa apreciable de ningún tipo, pero en cambio el puente ofrece en cada uno de los brazos dos pequeños botoncitos de oro que resaltan sobre el fondo oscuro del bronce oxidado.

\section{III.2. Medidas y composición}

Dimensiones: longitud máxima en el puente, $81 \mathrm{~mm}$.; sección media de la aguja, $3 \mathrm{~mm}$.; sección máx. del brazo, $6.5 \mathrm{~mm}$.; anchura máx. del brazo, $17 \mathrm{~mm}$; diámetro máx. de las espiras del resorte, $12 \mathrm{~mm}$; diámetro máx. de los botones de oro, $25 \mathrm{~mm}$.; altura máx. de los botones, $2 \mathrm{~mm}$.

Análisis espectrográfico (ICP-MS001): cobre $(\mathrm{Cu}), 93.7$; estaño $(\mathrm{Sn}), 3.72$; plomo $(\mathrm{Pb}), 0.30$; níquel (Ni), 0.06; berilio $(\mathrm{Be}), 0,05$; arsénico $(\mathrm{As}), 0.04$; oro $(\mathrm{Au}), 0.03$; bario $(\mathrm{Ba}), 0.02$; cobalto $(\mathrm{Co}), 0.02$; molibdeno (Mo), 0.01; antinomio (Sb), 0.01 .

\section{III.3. Discusión: la nueva fíbula y su problemática}

Al tratarse de otro hallazgo superficial más en Granada, como la mayoría de los casos de tipo Huelva que conocemos hasta ahora, salvo las fíbulas de La Miel (Carrasco, Pachón y Pastor 1985; Carrasco, Pachón, Pastor y Gámiz 1987), Infantes (Mendoza, Molina, Arteaga y Aguayo 1981: 177, 188 ss., fig. 12f; Molina, Mendoza, Sáez, Arteaga, Aguayo y Roca 1983: 692-693, fig. 2e.) y la obtenida en un solar de Guadix (Carrasco, Pachón, Adroher y López en prensa a y b), las referencias contextuales no son posibles en el último ejemplar encontrado, en la medida que lo sería cualquiera de las recuperaciones estratigráficas. Pero en este caso las dificultades son aún mayores, porque la fíbula procede de una colección particular a la que llegó mediante su adquisición en el mercado de antigüedades. Este dato supone la ignorancia absoluta del yacimiento originario, ya que inicialmente solo pudo apuntarse que el hallazgo debía ser granadino porque las fuentes comerciales de procedencia eran precisamente locales. Indagando más profundamente en el ámbito vital del posible descubridor, se nos apuntó su procedencia de Casa Nueva, una pedanía de Pinos Puente, donde no conocemos absolutamente ningún yacimiento del Bronce Final y donde era muy complicado aceptar sin más la recuperación de una fíbula como la que presentamos. Pese a todo, Casa Nueva supone una cercanía inmediata al gran asentamiento protohistórico de Cerro de los Infantes, donde ya conocíamos una fíbula de codo tipo Huelva en asociación estratigráfica, por lo que -a priori- un hallazgo más tampoco desdecía profundamente lo conocido. Si a ello sumamos que unos veinte kilómetros al norte 
disponemos de otra fíbula en Puerto Lope (Carrasco y Pachón 1998a), era posible sin mayor profundización aceptar la nueva fíbula en el entorno norte de la Vega de Granada (Fig. 1:18), algo que luego confirmaría suficientemente el análisis compositivo de la aleación del ejemplar.

La nueva fíbula del sector norte de la Vega de Granada es, en suma, una más del cada vez mayor grupo de ejemplares antiguos de codo de tipo Huelva registrados en la provincia de Granada, semejante por la forma al de La Miel, Puerto Lope o Montejícar (Carrasco y Pachón 1998b). El tamaño y su configuración general se acercaría más al primero de esos ejemplares (Fig. 2:2), pero la forma del resorte y su carácter unitario (una sola pieza) se asemejaría los segundos (Fig. 2: 3 y 4-5, respectivamente). Como curiosidad, el resorte que se acomoda a la izquierda del puente, tomando como orientación el pie de la fíbula, supone una novedad respecto de los casos de Granada, que siempre presentan el resorte a la derecha: esto la asemejaría a alguno de los casos de la Ría de Huelva, pero la forma se separa de ellas, lo mismo que la composición metálica.

Aunque ya se han hecho algunas observaciones sobre la dificultad de aceptar una procedencia fiable de esta fíbula, debe recordarse además que en el reborde noroccidental de la Vega de Granada, centrando nuestra atención en el espacio entre Casa Nueva y el propio Cerro de los Infantes en Pinos Puente, el conocimiento arqueológico y directo de esta zona nos induce a pensar en un origen más apropiado de este último yacimiento que, junto con la proximidad de la fíbula de Puerto Lope configuraría en esta comarca un triángulo en el que los hallazgos cobran una vital importancia y donde no resulta rara una recuperación semejante. Desgraciadamente, y como viene siendo habitual, estaríamos ante otra localización "superficial", en la que vuelve a faltar la necesaria asociación arqueológica; no obstante, las peculiaridades del nuevo hallazgo son trascendentales por sus implicaciones tipológicas, sociales y económicas.

Otro aspecto de importancia aportado por este reciente hallazgo es el decorativo. Hasta ahora, las características estéticas de las fíbulas tipo Huelva se habían limitado a la diferenciación de fajas en los brazos del puente, mediante abultamientos amorcillados de mayor o menor calibre, así como a anillos transversales que delimitaban esos abultamientos antes de alcanzar respectivamente el codo, el pie y el resorte. En muy pocos ejemplares los ensanchamientos se acompañan en la parte superior de un simple sistema de incisiones entrecruzadas que conforman normalmente rejillas romboidales o cuadrangulares y, en menor número, sistemas simples de espigas; incluso, más sencillamente, líneas incisas paralelas. Esta decoración resulta tan insignificante, que ni siquiera ha representado en los estudios fibulares existentes una diferenciación cualitativa respecto de los ejemplares lisos, ya que no suponían técnicamente una especial complejidad artesana en su confección, y es -por otro lado-un tema recurrente y no especialmente significativo de muchas producciones cerámicas. Es más, algunos ejemplares realizados en dos piezas son precisamente los que se han querido interpretar como producciones particularmente complejas de esta tecnología metálica. Afortunadamente, el hallazgo que ahora analizamos cambia totalmente estas apreciaciones tradicionales.

Es precisamente su aspecto decorativo el que le proporciona una personalidad única a la nueva fíbula. En él encontramos, junto a los característicos amorcillamientos y anillos delimitadores de sus brazos, sendos botones hemiesféricos huecos, realizados en oro, sujetos a la parte superior y central de los abultamientos por dos pivotes que parten de los brazos y se remachan por encima de una perforación en la que se insertan aquellos vástagos. Esta peculiaridad comporta por primera vez la comprobación de que estas fíbulas alcanzaron una significación realmente lujosa y, en este caso, de joyas que no conocíamos o que, al menos, no acabábamos de entender a partir de los hallazgos disponibles. De ahí su importancia como referencia fundamental en la incorporación de las mismas al corpus de los objetos de prestigio en el mundo de finales de la prehistoria, su comprensión en la iconografía de las estelas del Bronce Final y su relación con la demanda de tejidos de lujo en el paso del segundo al primer milenio a.C.

En otro orden de cosas, sin tener que reducirnos a la característica decoración del nuevo ejemplar, convendría recordar que las fíbulas de codo en general se han relacionado especialmente, y desde hace mucho tiempo, con la introducción en Iberia del uso de tejidos de lujo, posiblemente las producciones de 
lino teñidas con púrpura, tradicionalmente asociadas al intercambio a gran distancia con el Mediterráneo Oriental. Este hecho sirvió para corroborar las fechas tradicionales de nuestras fíbulas, en tanto que el comercio lejano de textiles se conectaba con la presencia fenicia peninsular en torno a los siglos IX/VIII a.C., algo que desmentía fechas más antiguas para este tipo de productos, aunque también otros cualificados investigadores amplían el espectro de esos contactos a una etapa anterior que vienen denominando precolonización (Almagro-Gorbea 2000, con la bibliografía anterior). Desde luego, aún admitiendo de modo general la introducción de tejidos exóticos, resultaba en cambio bastante más problemático aceptar con buen criterio el uso como elemento auxiliar de la vestimenta de lujo unas fíbulas un tanto rudas, que básicamente solo se componen de un alambre más o menos simple y pesado, retorcido aquí y allá a lo largo de su recorrido. Queremos decir con ello que, en general, con los datos tradicionales no se veían fíbulas especialmente complejas, ni realizadas en metales tan apreciados como para aceptarlas formando parte fehaciente del ajuar de lujo en el mobiliario doméstico de los grandes personajes del Bronce Final o de la primera época colonial, salvando su posible presencia en las estelas del suroeste, a partir de la interpretación en ellas de un diseño muy esquemático y siempre de difícil lectura. No es lo único, tampoco se conocen tumbas que confirmen tal aserto, y el problemático caso principesco de Casal do Meio (Portugal) ha proporcionado una fíbula en bronce de tipo ad occhio, muy diferente a las de Huelva. De nuevo, y en apoyo de todas estas cuestiones, viene a colación la fíbula granadina que aquí presentamos.

$\mathrm{Si}$ atendemos solo a su forma, nada se opone a una perfecta correspondencia de la nueva fíbula con el tipo Huelva. Ya hemos dicho que están presentes las típicas fajas en ambos brazos, con la conocida asociación de fajas e incisiones que las delimitan; a lo que se ha añadido la novedad de la inserción de los dos pequeños botoncitos de oro sujetos por un par de vástagos verticales, que no afectan básicamente a la estructura y conformación general de la misma. Pero la presencia de estos elementos áureos sí expresa la constatación más clara de que esta fíbula no representaba sólo el uso de objetos cotidianos de carácter práctico, sino que en ciertos casos debieron funcionar como adornos dotados con un claro sentido de prestigio. Esto explicaría también el gran tamaño que alcanzan algunas de estas fíbulas, una dimensión que sobrepasa la mera necesidad que debería corresponder a un objeto de carácter utilitario y práctico. Este hecho pone otra vez de actualidad, pero con más elementos de juicio, la posibilidad de encontrarnos ante objetos del ajuar funerario durante el Bronce Final, de ahí su presencia en las estelas y el hecho de su recuperación aislada, procedente quizás de tumbas expoliadas o arruinadas hace ya tiempo.

Relacionado con ello, en la zona occidental del yacimiento de Cerro de los Infantes, la que mira concretamente a Casa Nueva, entre el nuevo trazado de la carretera a Córdoba y el asentamiento, encontramos los restos de una de las necrópolis del poblado en la que se detectó recientemente la presencia de algunas estructuras tumuliformes inéditas (Pachón y Pastor 1994; Pachón y Gil en prensa), pero que desgraciadamente ya han sido alteradas parcialmente por la construcción de una vivienda levantada sobre uno de esos túmulos, pese a las denuncias interpuestas y la intervención judicial de la propia Delegación de la Consejería de Cultura en Granada. Aunque la interpretación inicial de esos túmulos se inclina por la época orientalizante, no debe extrañarnos que este espacio mortuorio viniese usándose desde el Bronce Final, si se atiende a algunos restos cerámicos superficiales de ese momento, por lo que tampoco debemos descartar que la fíbula en cuestión proceda de cualquiera de los ajuares de las sepulturas de ese momento.

De las cuestiones suscitadas hasta ahora, interesa extender las interpretaciones a tres aspectos: a) el uso de los tejidos, b) el tamaño de las fíbulas y c) el empleo del oro en las mismas, aunque existan implicaciones comunes. Todo denota una preocupación de usuarios y artesanos por la estética en general y el tratamiento de las fíbulas en particular, aunque sea la extensión del uso de ellas -y no su tamaño- lo que indique mejor un desarrollo paralelo y complementario en el consumo de los textiles. Por su parte, el gran tamaño de ciertos ejemplares de fíbulas y el lujo de su decoración, o de la propia composición metálica, sí podría relacionarse con determinados tejidos de calidad. 
A) El trabajo textil estuvo muy unido a los desarrollos económicos de las poblaciones asentadas en el interior de la provincia de Granada, conociéndose talleres de cierta importancia en yacimientos como Monachil (Arribas, Pareja, Molina, Arteaga y Molina 1974: lám. Vb) y en el propio Cerro de la Mora. Creemos que la producción metalúrgica derivada hacia la manufacturación de fíbulas hubo de desarrollarse paralelamente con la producción de telas, posiblemente de lino, cuyo aprovechamiento se conoce en contextos prehistóricos de Andalucía. Si a ello se unió el interés por textiles exóticos como la púrpura, a partir de la irrupción fenicia, o con la precolonización, no se trataría al menos de un hecho sorpresivo a tenor de la base cultural, económica y tecnológica que se vislumbra en el Bronce Final y, más concretamente, en el área del sudeste (Pachón, Pastor y Carrasco 1999). Las posibles concomitancias que pudiera haber entre las primeras fíbulas occidentales y las desarrolladas en el Mediterráneo Oriental, como defiende M. Almagro-Gorbea al amparo de la precolonización (2000: 714), es algo que aún se nos escapa y no vemos claro, porque -aunque algunos autores aceptan en Chipre fíbulas acodadas desde tiempos micénicos (Birmingham 1963; Blinkenberg 1926: 54; Borchhardt 1977: f. 5,d; Catling 1964: 42,a-d)- las formas no coinciden plenamente con las peninsulares y, lo que es más importante, los análisis espectrográficos aluden a producciones locales separadas de los típicos bronces orientales o del occidente hispano, además de estar documentadas arqueológicamente fases artesanales metalúrgicas en la provincia de Granada [Miel y Mora (Moraleda de Zafayona) y Guadix]. Algo definitivo para encuadrarlas tipológicamente como más modernas.

B) En cuanto al tamaño, las fíbulas de grandes dimensiones y acordes con un gran peso, podrían interpretarse mejor como elementos de prestigio que tienen un destacado papel en el desarrollo de los intercambios entre pueblos antiguos. Recuérdese que ninguno de estos grandes ejemplares se ha encontrado en ambientes habitacionales, aunque la falta de contexto arqueológico solo nos permite conocer que el caso de Cerro de la Miel (longitud máxima: $7.8 \mathrm{~cm}$ ) procede de un ambiente productivo de carácter metalúrgico, separado del área habitada de Cerro de la Mora; mientras que las fíbulas de codo tipo Huelva contextualizadas de menor tamaño corresponden al caso de la ciudad de Guadix $(5.5 \mathrm{~cm})$, asociada a un taller metalúrgico también pero de época más tardía y sin datos sobre su posible relación con espacios domésticos; mientras que la fíbula de Los Infantes, de dimensiones algo menos reducidas que la de Guadix $(6.4 \mathrm{~cm}$.), procede claramente de un ambiente de hábitat. La nueva fíbula, hasta ahora la más lujosa de las conocidas, muestra una longitud máxima conservada en el puente de $8.1 \mathrm{~cm}$, por lo que, atendiendo a todos estos datos, parece existir una pauta clara que relacionaría tamaño, lujo y prestigio.

En ese último aspecto de los objetos de prestigio, los dones pudieron cumplir un importante papel en cuestiones como los mecanismos de control de las buenas relaciones entre diferentes comunidades y, así, garantizar el mantenimientos de los contactos comerciales. En este sentido, el uso de objetos poco útiles en lo cotidiano adquiere fundamento dentro de las ceremonias de recepción ante el extranjero, o ante la propia comunidad, como referentes del prestigio y categoría social del usuario. Pero no queremos interpretar todas estas enormes fíbulas (la que estudiamos o la de La Miel) dentro del problema del intercambio de bienes, porque supondría aceptar un origen foráneo de las mismas y nuestra línea de investigación defiende precisamente el carácter autóctono. Con independencia de que también aceptamos la precolonización con un indudable traspaso de objetos entre los grupos sociales endógenos y exógenos, las grandes fíbulas que aquí estudiamos debieron quedar fuera de esos intercambios como las muestras espectrográficas parecen indicar. Lo que debe quedar claro es el carácter de prestigio de tales objetos, comprobado por el sentido funerario de la fíbula también de gran porte de Cerro Alcalá (Carrasco, Pachón, Pastor y Lara 1980), aunque no se trate en este caso de una fíbula tipo Huelva, así como su valor suntuario que también expresa la importante decoración de la nueva fíbula, donde a lo estético se une sus considerables dimensiones, ahora en un claro ejemplar del tipo Huelva.

C) En el sistema decorativo también encontramos apoyo para fundamentar la autoctonía de la nueva fíbula. Esa decoración consiste en sendos botones (hemiesferas huecas) de oro, sujetos al puente por dos 
pivotes que se remachan en los polos respectivos de cada botón. Sin considerar en principio el material en que se realizaron, esas hemiesferas ya las conocemos en un sistema decorativo parecido, pero realizadas en bronce/cobre y sujetas a la superficie de determinados recipientes cerámicos. La diferencia estriba en que en la decoración cerámica los botones no van perforados ni sujetos por un pivote, sino grapados, porque la arcilla blanda es más que suficiente para sujetarlos a su superficie antes de la cocción; en cambio, en una fíbula metálica, un uso semejante de la técnica sería imposible al disponer el bronce de una temperatura de fusión mucho más elevada que el oro, lo que provocaría la fusión del botón si pretendiésemos insertarlo sobre un puente de fíbula blando (fundido o en semifusión). La solución más sencilla es la que se adoptó: ajustar los botones a unos apéndices diseñados previamente sobre el puente de la fíbula, insertarlos a través de la perforación polar de los botones y remacharlos ligeramente para evitar que saltaran con posterioridad. Esta concomitancia, que nos parece evidente, plantea de nuevo la problemática de las cerámicas decoradas con botones de cobre/bronce que ya hemos discutido en otro sitio (Carrasco, Pachón, Pastor y Gámiz 1983: 61 ss.):

Según nuestras directas excavaciones en Cerro de la Miel y Cerro de la Mora, las cerámicas con decoración metálica pertenecen básicamente a un momento central del Bronce Final, sin descartar que su origen en estos yacimientos alcanzara el Bronce Tardío. La excavación de 1980 en Cerro de los Infantes proponía en su secuencia cultural un cuenco con decoración metálica incrustada, correspondiente a la misma fase del hallazgo de la fíbula de codo, en el horizonte III del yacimiento (Mendoza, Molina, Arteaga y Aguayo 1981: fig. 12h); una lógica situación que parecía olvidar que la vasija de referencia era una recuperación superficial de otro sitio del asentamiento. Los paralelos que se conocían entonces en el Suroeste, gracias a los contenidos de los túmulos de Setefilla, permitieron situar 'razonablemente' esos vestigios en el Bronce Final tartésico, en un momento equivalente a la fase II del Bronce Final del Sudeste (Molina 1978), cuando -prácticamente-apenas se contaba con cerámicas semejantes que estratigráficamente pudieran considerarse de ese últim̧o periodo en Andalucía Oriental. Sí existía un hallazgo más antiguo de Cerro de la Encina en Monachil (Arribas, Pareja, Molina, Arteaga y Molina 1974: fig. 68:92), pero la interpretación generalizadora que se le dio, dentro de un amplio Bronce Final, tampoco permitió una adscripción cronocultural válida para nuestras investigaciones.

Las cerámicas con incrustaciones metálicas tampoco encuentran refrendo en las estratigrafías del Suroeste andaluz, por lo que es problemático generalizar las fechas que se dieron a los hallazgos de la necrópolis de Setefilla; lo que supone olvidar que son muchos los investigadores que las consideran fechas excesivamente cercanas a nosotros (Bendala 1992: 35; Torres 1996), lo que no ha llegado a impedir que, sin embargo, se creara una cierta escuela entre los investigadores bajoandaluces, caracterizada por las cronologías a la baja, que no tuvieron ningún inconveniente incluso para situar las producciones cerámicas de Cogotas I, prácticamente en los primeros momentos de la Edad del Hierro. Estas cuestiones llegaron a plantear polémica entre las opiniones que se emitían desde Sevilla y lo que postulaban los investigadores de Granada, a raíz de estratigrafías prototipo del suroeste que se centraban en Cerro Macareno y Carmona, fundamentalmente. Posteriormente, investigadores de otras universidades intervinieron en el asunto, señalando que en la zona central andaluza las fechas podían funcionar mejor como se estaba postulando en Andalucía Oriental (Martín de la Cruz 1989: 121 ss.); desgraciadamente, estas puntualizaciones siguieron siendo ignoradas en muchos casos, como se aprecia en otro trabajo de esas mismas fechas (Pellicer 1989). Por fortuna, excavaciones en otros yacimientos referenciales de la provincia de Sevilla han empezado a recomponer la secuencia cultural de la prehistoria reciente en la Baja Andalucía (Cardenete, Gómez, Jiménez, Lineros y Rodríguez 1991: 571 ss.), adecuándola a la secuencia general que podemos encontrar a lo largo del Guadalquivir, gracias a otras investigaciones como las de Torreparedones, Córdoba (Cunliffe y Fernández 1999) o Los Alcores de Porcuna, Jaén (Roos 1997). Precisamente, hasta no hace mucho, el único hallazgo estratificado del que teníamos noticias, en ese área geográfica, parecía haberse producido también en Setefilla, donde se apreció un fragmento cerámico con decoración metálica en el estrato XIII de aquel yacimiento, interpretado 
por los excavadores de Setefilla como horizonte estratigráfico de transición hacia el Bronce Final Pleno (Aubet, Serna, Escacena y Ruiz 1983: 70).

Los hallazgos de estas cerámicas alcanzan hoy un área de dispersión que sobrepasa ampliamente lo andaluz, aunque los ejemplos más antiguos seguirían centrados en esta región (Lucas Pellicer 1995). De los hallazgos extra-andaluces llama la atención el del yacimiento levantino de Caramorro II, junto a Elche, donde se recuperó una ollita de perfil en ese con botoncitos metálicos (González Prats y Ruiz Segura 1992: 17 ss., fig. 4:6), que recibió una fecha entre los siglos IX y VIII a.C; mientras en Extremadura llegan al Cobre Pleno (según nos informa Don A. González Cordero). Frente a ello, los nuevos hallazgos andaluces apuntan hacia el ascenso en la cronología de estos peculiares materiales cerámicos, como veníamos manteniendo desde nuestros hallazgos granadinos; así, en un reciente estudio general sobre el poblamiento del Bronce Final/Hierro en la Cuenca Media del Guadalquivir se advierte sobre su presencia entre otros asentamientos (Murillo 1994: fig. 5,66), en la Vega de Santa Lucía, Saetilla (Murillo 1987, 1990a, 1990b y 1990c) y Montoro (Martín de la Cruz 1987), donde la secuencia estratigráfica podría adjudicarles una banda cronológica entre los siglos X y IX a. C., al margen de las posibles perduraciones posteriores (necrópolis de Setefilla). Estas fechas empiezan a cuadrar mejor con lo que venimos postulando para Andalucía Oriental.

La asociación de esta cerámica en La Miel junto a la fíbula de codo, unida a las fechas que hoy vemos en otros yacimientos andaluces desde el siglo X a.C., o incluso el XI, mostrarían un ambiente antiguo donde, si es factible relacionar tan peculiar decoración alfarera con la de los remates áureos de la fíbula aquí estudiada, quizás pueda apoyarse una producción indígena y arcaica para este tipo de productos o, al menos, una producción al gusto local. Estaríamos ante una fíbula emparentada cultural y cronológicamente con la fíbula de La Miel. Indudablemente, los caracteres de la aleación apoyarán definitivamente un origen granadino o, más genéricamente, del área suroriental andaluza.

Por otro lado, la inclusión de elementos metálicos nobles en esta fíbula, por su carácter único, aporta un cariz exclusivo que puede hacer pensar en una hipotética manufactura extrapeninsular, ya que no conocemos tal peculiaridad en fíbulas peninsulares anteriores a momentos ibéricos y cuando aparecen son realizaciones que nada tienen que ver con los modelos fibulares que ahora analizamos. Este hecho obliga a mirar hacia áreas geográficas ajenas a la Península, donde encontramos un paralelo de fíbula en oro que interesa destacar por su posible relación con las del tipo Huelva:

Se trata de un ejemplar griego (Fig. 2: 6) que recuperó H. G. Buchholz de otros investigadores procedente de Levkandi (Euboia). Aparecida en la tumba número 38 de la necrópolis de Toumba, corresponde a un tipo único en la zona del Egeo, realizada además completamente en oro. Su configuración es plana con los brazos del puente curvados y lisos y la aguja recta (Buchholz 1986: 230). De este ejemplar debe destacarse, junto a su manifiesta antigüedad en el Sub-Protogrométrico II (Sapouna 1995: fig. 49), una cierta similitud con la del Cerro de la Miel. Su perfil es muy plano y los brazos del puente, igualmente curvados con sección oblonga, o elíptica, muy similar a nuestra pieza, así como su aguja recta. Sin embargo, un matiz diferenciador de la fíbula griega sería la falta de decoración en sus brazos, así como presentar una mortaja más corta, de tipología diferente. Es posible que esta fíbula tenga alguna similitud de origen con nuestras fíbulas más antiguas, pero por su condición de ejemplar único, no conocemos su desarrollo posterior ni su entronque antiguo, aunque es factible que proceda en último caso de algún tipo de fíbula de violín, lo que tampoco aclararía el origen ni las derivaciones propias que pudieron conducir al tipo aquí estudiado.

Para terminar, tampoco olvidemos que no se trata de un dato casual la composición metálica reconocida en la nueva fíbula, donde encontramos un 93.7 de cobre $(\mathrm{Cu})$ y un 3.72 de estaño ( $\mathrm{Sn}$ ). Esta peculiaridad incluiría nuestro ejemplar entre el caso extremo de la fíbula de Puerto Lope, que llega a alcanzar el 96.79 de cobre, y la acercaría también a una de las fíbulas procedentes de la zona de Guadix, que ofrece 3.51 de estaño. Pero, si definitiva es la concentración de $\mathrm{Cu} / \mathrm{Sn}$, aún lo es más la presencia de arsénico (As), que constituye un oligoelemento primordial de la composición en las aleaciones de producciones metalúrgicas 
antiguas de Andalucía Oriental y de Granada en particular, separando estas manufacturas de las conocidas del occidente peninsular y de las del resto del Mediterráneo. Estas peculiaridades son apreciables en la base de las composiciones metálicas que se consideran antiguas, dentro de la escala de aleaciones que hemos considerado para las fíbulas arcaicas del Sureste peninsular (aleación pobre de bronce-Cu+Sn-con presencia de arsénico) (Carrasco y otros 1999). La nueva fíbula podría también explicar la existencia de un tercer taller metalúrgico diferente de los ya detectados en Moraleda de Zafayona y Guadix en la búsqueda de una aleación propicia para elaborar una fíbula que permitiese asociar eficazmente elementos de bronce y oro, aunque lo más probable es que solo aludan a la existencia de un tercer taller metalúrgico diferente de los ya detectados en Moraleda de Zafayona y Guadix.

En definitiva, todas esas peculiaridades compositivas, así como las concomitancias que se han puesto de manifiesto entre la fíbula de Cerro de la Miel y otras de Granada, respecto de la de Casa Nueva/P. Puente, incluso sin olvidar las asociaciones con las cerámicas decoradas con botones metálicos, nos inclinan a pensar que el origen de la nueva fíbula debe ser hispano y, posiblemente granadino, pero además que se trata de una producción peculiar dentro de los ejemplares de gran tamaño, pensado especialmente para los rituales propiamente funerarios y de prestigio.

\section{BIBLIOGRAFÍA}

ALBELDA, J. (1923): "Bronces de Huelva. Espagne", Revue Archéologique: 222 ss.

ALMAGRO BASCH, M. (1940a): "El hallazgo de la Ría de Huelva y el final de la Edad del Bronce en

el Occidente de Europa", Ampurias II: 85 ss.

—_ (1940b): "La cronología de las fíbulas de codo", Saitabi III: 1 ss.

- (1957): "Las fíbulas de codo de la ría de Huelva. Su origen y cronología, Cuadernos de la Escuela Española de Roma IX: 9 ss.

- (1957-58): “A propósito de la fecha de las fíbulas de Huelva”, Ampurias XIX-XX: 198 ss.

- (1958): El depósito de la Ría de Huelva, Inventaria Arqueológica. España, 1-4: E.1, Madrid.

ALMAGRO-GORBEA, M. (2000): "La 'precolonización fenicia' en:la Península Ibérica", IV Congreso Internacional de Estudios Fenicios y Púnicos II: 711-721. Cádiz.

ARRIBAS, A.; PAREJA, E.; MOLINA, F.; ARTEAGA, O. y MOLINA F. (1974): Excavaciones en el poblado de la Edad del Bronce 'Cerro de la Encina', Monachil (Granada). El corte estratigráfico ${ }^{\circ}$ 3, EAE 81, Madrid.

AUBET, Mª E., ed. (1989): Tartessos. Arqueología Protohistórica del Bajo Guadalquivir. Sabadell, Ed. Ausa.

AUBET, Ma E.; SERNA, Ma R.; ESCACENA, J. L. y RUIZ, M. M. (1983): La Mesa de Setefilla. Lora del Río (Sevilla). Campaña de 1979, EAE 122, Madrid.

BENDALA, M. (1992): "La problemática de las necrópolis tartésicas”, en BLÁNQUEZ, J. y ANTONA, V.: 27-36.

BIRMINGHAM, J. (1963): "The development of the fibula in Cyprus and the Levant", Palestine Exploration Quaterly 95: 80-112.

BLINKENBERG, Chr. (1926): Fibules grecques et orientales, Historik-filologiske Meddelelser XIII, 1, København.

BLÁNQUEZ, J. y ANTONA, V. (1992): Congreso de Arqueología lbérica. Las necrópolis, Serie Varia 1, Universidad Autónoma, Madrid.

BORCHHARDT, H. (1977): "Frühe Griechische Schildformen", en BUCHHOLZ - WIESNER (Eds.): 1-56. BOSCH GIMPERA, P. (1926): "Huelva", Reallexicon der Vorgeschichte 5: 5. 
BUCHHOLZ, H. G. (1986): "Ein kyprischer Fibeltypus und seine auswärtige Verbreitung", Cyprus between the Orient and the Occident: 223-245. Acts of the International Archaeological Symposium, Nicosia, 8-14 sept. 1985, Nicosia.

BUCHHOLZ - WIESNER (Eds.) (1977): Archäologia Homerica. 1.

CARDENETE, E., GÓMEZ, M. T., JIMÉNEZ, A., LINEROS, R. y RODRÍGUEZ, I. (1991): "Excavaciones arqueológicas de urgencia en el solar de la calle Costanilla Torre del Oro s/n. Carmona (Sevilla)", $A A A$ '89 III: 563-574.

CARRASCO, J. y PACHÓN, J. A. (1998a): "La fíbula de codo tipo Huelva procedente de la comarca de Puerto Lope/Íllora (Granada)", Tomás Quesada Quesada. Homenaje: 877-896. Granada, F. Filosofía y Letras.

_ـ (1998b): "Las fíbulas de codo tipo Huelva de Montejícar, Granada", Florentia Iliberritana 9: 423-433. Granada.

_- (en prensa): Producción y metalurgia en las sociedades finales del bronce en el sureste: las fíbulas de codo de tipo Huelva. Análisis histórico-arqueológico, técnico y estadístico de una producción meridional en el Bronce Final de la Península Ibérica. Granada.

CARRASCO, J.; PACHÓN, J. A.; ADROHER, A. y LÓPEZ, A. (en prensa, a): “Un área de transformación metalúrgica del bronce final en Guadix (Granada, España)", Arethusa 1. Roma.

- (en prensa, b): "Taller metalúrgico de fines del Bronce en Guadix (Granada): Nueva contribución a la contextualización de las fíbulas de codo tipo Huelva en Andalucía Oriental", BSAA, Valladolid.

CARRASCO, J.; PACHÓN, J.A.; ESQUIVEL, J. A. y ARANDA, G. (1999): "Estudio tecno-tipológico y estadístico de las fíbulas de codo tipo Huelva de la Península Ibérica", Complutum 10: 123-142.

CARRASCO, J.; PACHÓN, J. A. y PASTOR, M. (1985): "Nuevos hallazgos en el conjunto arqueológico del Cerro de la Mora. La espada de lengua de carpa y la fíbula de codo del Cerro de la Miel (Moraleda de Zafayona, Granada)", Cuad. Preh. Gr. 10: 265-333.

CARRASCO, J.; PACHÓN, J. A.; PASTOR, M. y GÁMIZ, J. (1987): La espada de lengua de carpa del Cerro de la Miel (Moraleda de Zafayona) y su contexto arqueológico. Nuevas aportaciones para el conocimiento de la metalurgia del Bronce Final en el sudeste peninsular. Moraleda de Zafayona.

CARRASCO, J.; PACHÓN, J. A.; PASTOR, M. y LARA, I. (1980): "Hallazgos del Bronce Final en la provincia de Jaén. La necrópolis de Cerro Alcalá (Torres, Jaén )”, Cuad. Preh. Gr. 5: 221-236.

CATLING, H. W. (1964): Chypriot Bronzework in the Mycenaean World, Oxford.

CUNLIFFE, B. y FERNÁNDEZ, Ma C. (1999): The Guadajoz Project. Andalucía in the First Millenium $B C, 1$. Torreparedones and its hinterland, OUCA, Monograph 47, Oxford.

DÍAZ, E. (1923): "Objetos de bronce de la Ría de Huelva", Boletín de la Sociedad Española de Antropología 2, Madrid.

FERRER, E.; GARCÍA, F. J.; GONZÁLEZ, D.; MUÑOZ, E. y MORO, F. J. (1997): "Dos notas sobre el depósito de la Ría de Huelva", Spal 6: 67-85.

GÓMEZ MORENO, M. (1923): "Hallazgo arqueológico en el puerto de Huelva", BRAH 38: 89 ss.

GONZÁLEZ, C.; SÁNCHEZ, P. y DOMINGO, M. (1987): "University of Granada. Radiocarbon Dates IV”, Radiocarbon 29, 3: 381-388.

GONZÁLEZ PRATS, A. (1990): Nueva luz sobre la protohistoria del Sudeste. Alicante.

GONZÁLEZ PRATS, A. y RUIZ SEGURA, E. (1992): "Un poblado fortificado del Bronce Final en el Bajo Vinalopó", Estudios de Arqueología Ibérica y Romana, Homenaje a E. Pla Ballester, SIP 14: 17-27. GUZZO,P. G. (1969): "Considerazioni sulle fibule del ripostiglio dal Ría de Huelva”, RSP XXIV-2: 79-141. LUCAS PELLICER, Ma R. (1995): "Cerámicas con apliques de metal", BAEAA 35: 107-122, Madrid. MARTÍN DE LA CRUZ, J. C. (1987): El Llanete de los Moros. Montoro, Córdoba, EAE 151, Madrid. _ (1989): "El Bronce en el Valle Medio del Guadalquivir", en AUBET, Ma E. (Ed.):121-143. 
MENDOZA, A.; MOLINA, F.; ARTEAGA, O. y AGUAYO, P. (1981): "Cerro de los Infantes (P. Puente, Provinz Granada). Ein Beitrag zur Bronze und Eisenzeit in Oberandalusien", M.M. 22: 171-210.

MOLINA, F. (1978): "Definición y sistematización del Bronce Tardío y Final en el Sudeste de la Península Ibérica", Cuad. Preh. Gr. 3: 159-232.

MOLINA, F.; MENDOZA, A.; SÁEZ, L.; ARTEAGA, O.; AGUAYO, P. y ROCA, M. (1983): "Nuevas aportaciones para el estudio del origen de la cultura ibérica en la Alta Andalucía. La campaña de 1980 en el Cerro de los Infantes", CNA XVI: 689-707, Zaragoza.

MURILLO, J. F. (1987): “Un nuevo yacimiento del Bronce Final en la provincia de Córdoba. La Saetilla, Palma del Río", Ariadna 2: 13-26.

(1990a): "El inicio de la Protohistoria en la Cuenca Media del Guadalquivir: los yacimientos de Vega de Santa Lucía y la Saetilla (Palma del Río, Córdoba), Fons Mellaria '89, Curso de Arqueología: 59-86. (1990b): “"Fondos de cabaña' de Vega de Santa Lucía (Palma del Río, Córdoba)”, AAA'87 III: 147-150. (1990c): "Excavación arqueológica de urgencia en La Saetilla (Palma del Río, Córdoba), AAA ‘87 III: 212-214.

(1994): La cultura tartésica en el Guadalquivir Medio, Ariadna 13-14, Palma del Río, Córdoba.

PACHÓN, J. A. (1997): El Cerro de la Mora y la metalurgia del Bronce Final a la luz de ciertos artefactos. Tesis Doctoral inédita, Univ. de Granada.

PACHÓN, J. A. y GIL, A. E. (en prensa): "Una necrópolis tumular protohistórica en Pinos Puente, Granada. Análisis histórico-cultural, geológico y prospección geofísica", Cuad. Preh. Gr., Homenaje a A. Arribas Palau, Granada.

PACHÓN, J. A. y PASTOR, M. (1994): “Túmulos protohistóricos en la provincia de Granada”, Rev. de Arqueología 154: 24-29, Madrid.

PACHÓN, J. A.; PASTOR, M. y CARRASCO, J. (1999), "Los problemas de transición en las sociedades protohistóricas del sureste. El cerro de la Mora (M. de Zafayona, Granada)", II Congreso de Arqueología Peninsular, III: Primer Milenio y Metodología: 129-140, Madrid.

PELLICER, M. (1986): “El Bronce Reciente e inicios del Hierro en Andalucía Oriental”, Habis 17: 433-475. (1989): "El Bronce Reciente y los inicios del Hierro en Andalucía Occidental", en AUBET, Mª E. (ed.): Tartessos ...: 147-187.

_ (1993): "Una visión sintética de la Prehistoria de Andalucía: Neolítico-Bronce Reciente”, Spal 1: 99-105.

ROOS, A. Ma (1997): La sociedad de clases, la propiedad privada y el Estado en Tartesos. La visión de su proceso histórico desde la arqueología del 'Proyecto Porcuna', Tesis doctoral inédita, Granada.

RUIZ-GÁLVEZ PRIEGO, Ma L. (1990): "La metalurgia de Peña Negra I”, en GONZÁLEZ PRATS, A.: Nueva luz ....: 317-343.

- (1993): "La novia vendida", Spal 1: 219-251.

- (1995): Ritos de paso y puntos de paso. La ría de Huelva en el mundo del Bronce Final Europeo, Complutum Extra 5.

SAPOUNA, E. (1995): Eretria. Site and Museum, Ministry of Culture, Atenas.

TERRERO, J. (1944): Armas y objetos de bronce extraídos en los dragados del puerto de Huelva, Madrid. TORRES, M. (1996): "La cronología de los túmulos A y B de Setefilla. El origen del rito de la cremación en la cultura tartésica", Complutum 7: 147-162. 

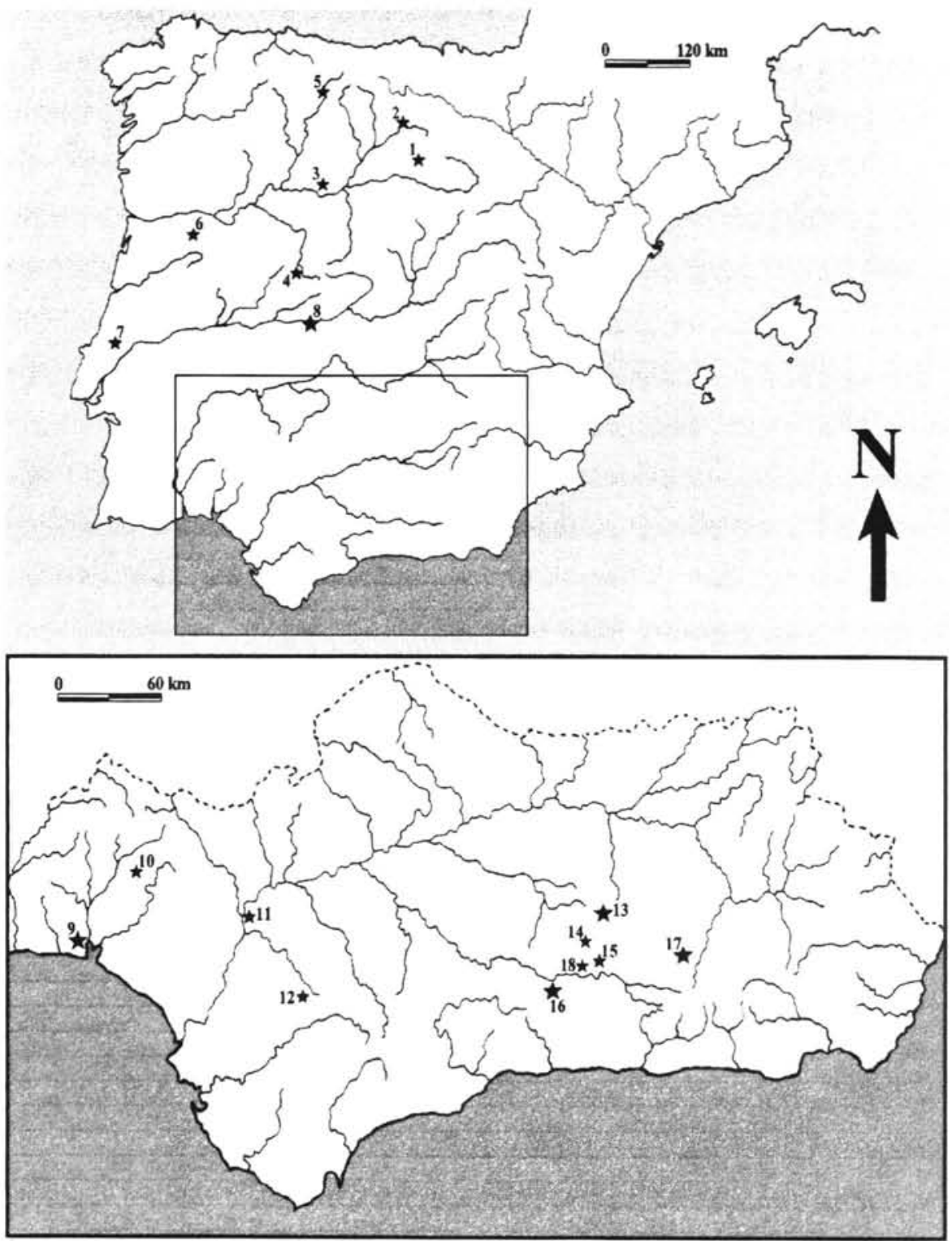

Figura 1.- Arriba.- Hallazgos peninsulares de fíbulas de codo de tipo Huelva, excluyendo los andaluces. (Las estrellas más grandes señalan más de una fíbula): 1.- Yecla de Silos (Burgos); 2.- Palencia o Burgos (Museo de Barcelona) 3.- San Román de la Hornija (Valladolid); 4.- El Berrueco (Salamanca); 5.- Sabero (León); 6.- Mondim da Beira, Viséu (Portugal); 7.- Alto das Bocas, Extremadura (Portugal); 8.- Talavera la Vieja (Cáceres). Abajo.- Hallazgos andaluces: 9.- Ría de Huelva; 10.- Valverde del Camino (Huelva); 11.- Coria del Río (Sevilla); 12.- El Coronil (Sevilla); 13.- Montejícar (Granada); 14.- Illora/Puerto Lope (Granada); 15.- Cerro de los Infantes, Pinos Puente (Granada); 16.-Cerro de la Miel, Moraleda de Zafayona (Granada); 17.- Guadix (Granada); 18.- Casa Nueva/Pinos Puente (Granada). 

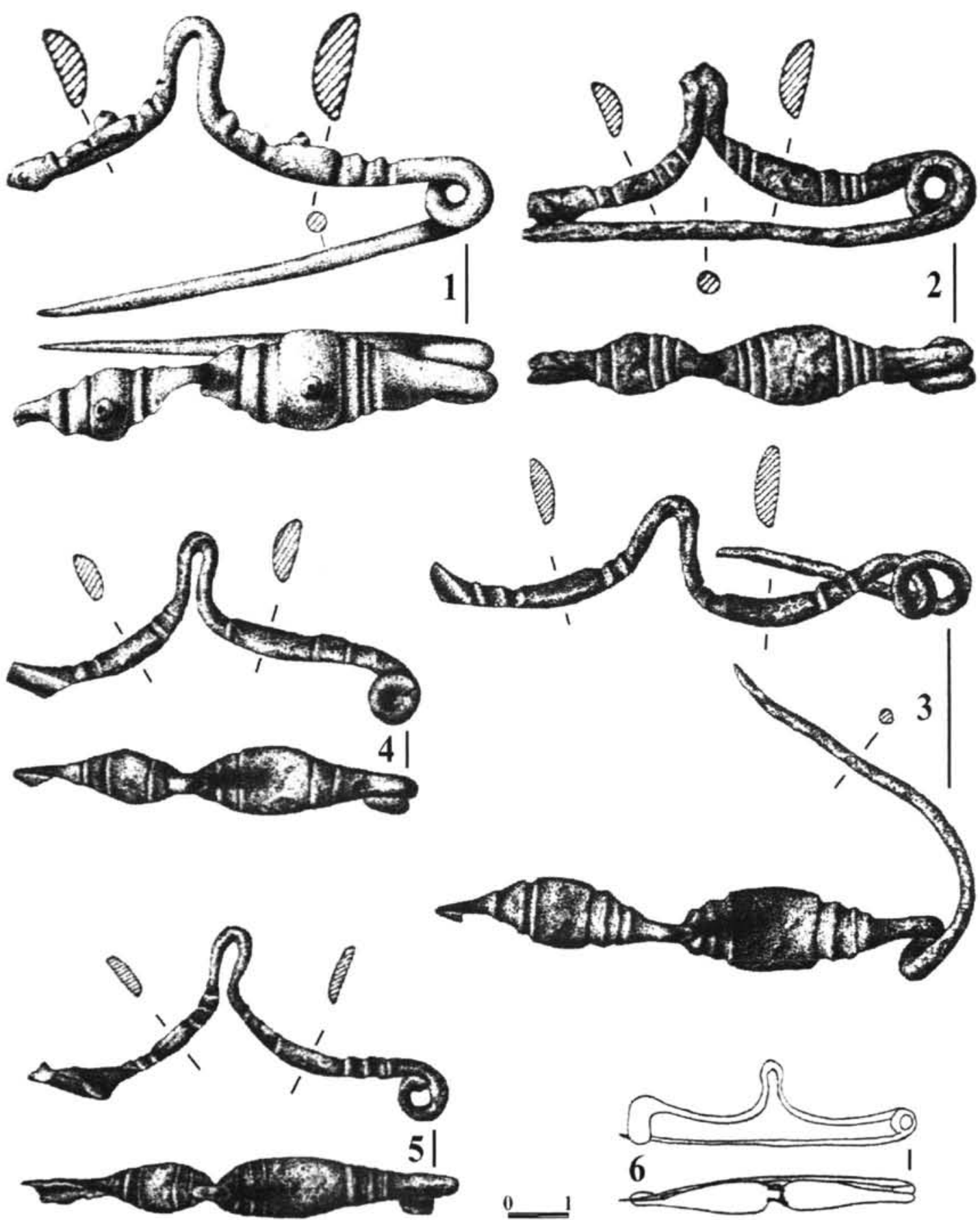

Figura 2.- Fíbulas de codo de tipo Huelva (1 a 5): 1.- Casa Nueva/Pinos Puente; 2.-Cerro de la Miel; 3.- Puerto Lope; 4-5.- Montejícar; 6.- Fíbula de Levkandi, Euboia (según Buchholz 1986). La nº 6 sin escala. 

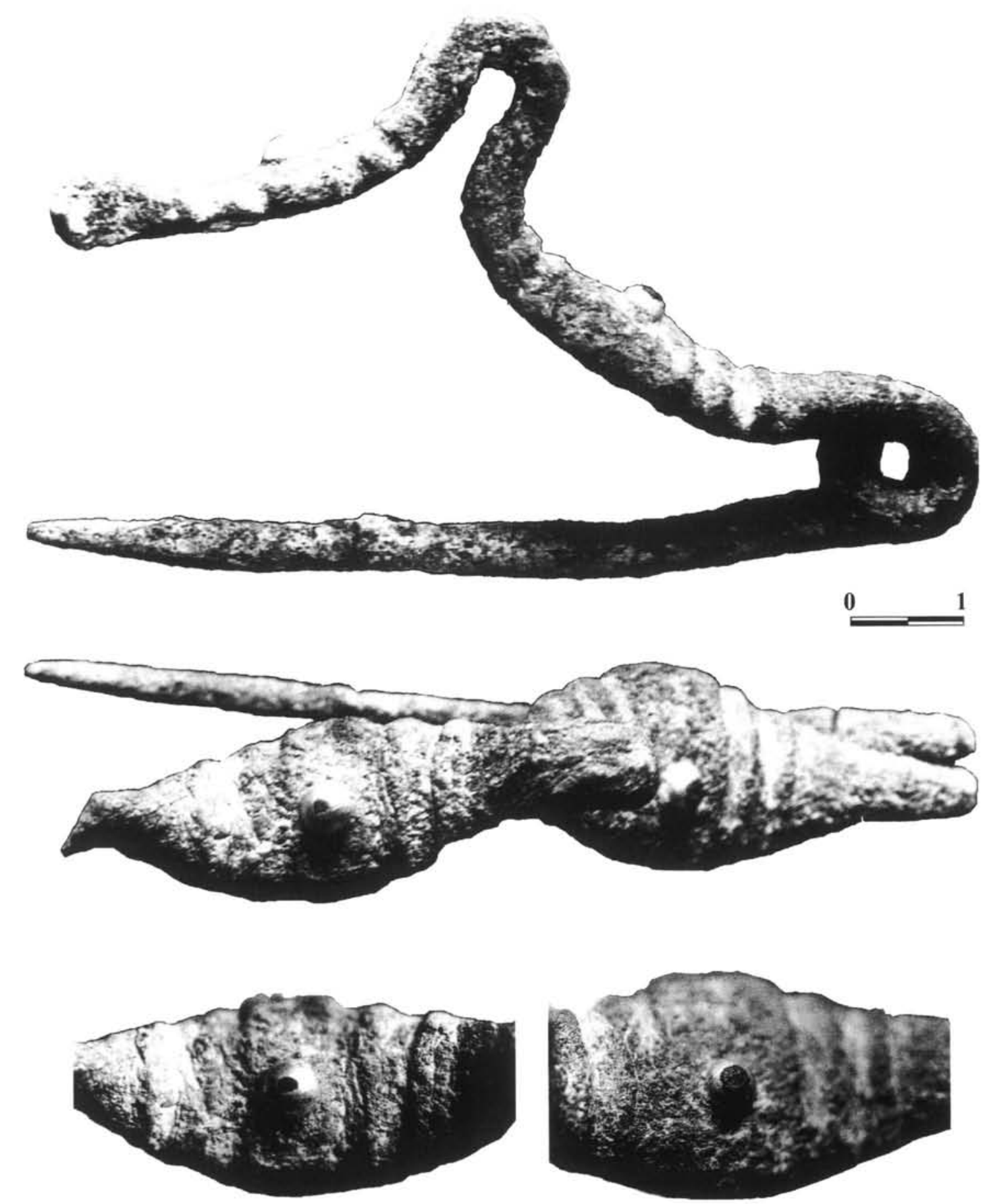

Lámina I.- Fíbula de codo de Casa Nueva/Pinos Puente. De arriba abajo: vistas lateral, superior y detalle de los brazos con los botones de oro. 